\title{
Georges Canguilhem e a construção do campo da Saúde Coletiva brasileira ${ }^{1}$
}

\author{
José Ricardo de Carvalho Mesquita Ayres \\ Professor Titular do Departamento de Medicina Preventiva - Faculdade de Medicina USP \\ ircayres@usp.br
}

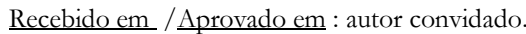

Como citar este artigo: Ayres, José Ricardo de Carvalho Mesquita. "Georges Canguilhem e a construção do campo da saúde coletiva brasileira”. Intelligere, Revista de História Intelectual, São Paulo, v. 2, n. 1 [2], p. 139-155. 2016. Disponível em < http://revistas.usp.br/revistaintelligere>. Acesso em dd/mm/aaaa.

Resumo: A epistemologia histórica tem desempenhado um papel destacado no desenvolvimento da Saúde Coletiva brasileira. Nascido como um movimento simultaneamente acadêmico, de busca de novas bases conceituais para um campo científico comprometido com as causas sociais, e político, de resistência contra a ditadura civil-militar implantada no Brasil em 1964, o chamado Movimento da Reforma Sanitária Brasileira encontrou na epistemologia histórica francesa um poderoso aliado. Este artigo busca revisitar os principais traços desta relação, enfocando particularmente os trabalhos inaugurais de Sérgio Arouca e Cecília Donnangelo e a Teoria do Processo de trabalho em Saúde desenvolvida no Departamento de Medicina Preventiva da Faculdade de Medicina da Universidade de São Paulo. A discussão está centrada no modo como, de um lado, os conceitos filosóficos de Canguilhem, tais como o caráter normativo da vida e de seu conhecimento, a descontinuidade qualitativa entre os fenômenos normais e patológicos e a definição de saúde orientada pela noção de valor e, de outro lado, a metodologia histórica de Canguilhem, focada no desenvolvimento racional dos conceitos como núcleo da pesquisa histórico-epistemológica, o reconhecimento das influências “externas" sobre os desenvolvimentos científicos, tais como condições sociais e tecnológicas, e o papel positivo atribuído aos obstáculos, falhas e acidentes no progresso das disciplinas científicas, foram todos cruciais para promover a articulação entre os interesses políticos e acadêmicos do Movimento, e ainda permanecem sendo elementos desafiadores para as reflexões históricas e filosóficas da Saúde Coletiva.

Palavras-chave: Saúde Pública/história; Medicina Preventiva; Medicina Social; Epistemologia; Saúde Coletiva; Georges Canguilhem.

\footnotetext{
1 Trabalho vinculado ao projeto "História da Saúde Coletiva no Estado de São Paulo: emergência e desenvolvimento de um campo de saber e práticas" (FAPESP 2013/12137-0) e apresentado ao Simpósio "Canguilhem, a História e os Historiadores", organizado pelo Departamento de História da Faculdade de Filosofia, Letras e Ciências Humanas da USP, em 15 de setembro de 2015.
} 


\title{
Georges Canguilhem and the development of Brazilian Public Heatlh field
}

\begin{abstract}
Historical epistemology has played an important role in the development of modern Brazilian Public Health or "Saúde Coletiva" (Collective Health). Born as an academic search for new conceptual foundations of a social committed field of scientific knowledge, as well as a social political movement against civil-military dictatorship implanted in Brazil in 1964, the so called Brazilian Sanitary Reform Movement found in the French historical epistemology, particularly in the works of Georges Canguilhem, a powerful ally. This paper aims to revisit the main features of this relationship, focusing in particular the inaugural works of Sergio Arouca and Cecília Donnangelo and the Health Work Process Theory as developed in the Department of Preventive Medicine of the Medical School of the University of São Paulo. The discussion is centered in the way Canguilhem's philosophical concepts, such as the normative character of life and of its knowledge, the qualitative discontinuity between normal and pathological phenomena and the value oriented definition of health on one hand, and on the other hand, Canguilhem's historiographical method, focused on the rational development of concepts as the core subject of the historical-epistemological research, the acknowledge of "external" influences over scientific developments, such as social and technological conditions, and the positive role attributed to obstacles, failures and accidents in the progress of a scientific discipline were all crucial to promote the intertwining of the political and academic goals of the Movement and still remain a challenging element for the development of the philosophical and historical reflections of the field of "Saúde Coletiva".
\end{abstract}

Keywords: Public Health/History; Preventive Medicine; Social Medicine; Epistemology; Collective Health; Georges Canguilhem.

\section{Canguilhem por um sanitarista, algumas notas introdutórias}

Este artigo não é um trabalho de historiador, mas talvez seja útil para historiadores. Explico. Sou médico sanitarista e professor da Saúde Coletiva. Entre as diversas atividades abarcadas por um campo amplo e plural como este, tenho me dedicado também a estudar suas raízes históricas e bases epistemológicas e conceituais. Como outros em meu campo, aventureime por sendas interdisciplinares - não sem o risco sempre implicado nesses trânsitos - que acabaram por me levar à epistemologia histórica. Cheguei aí, portanto, não por um interesse estritamente historiográfico ou filosófico, mas por ver nesse diálogo possibilidades de melhor entender o que fazemos e o que não conseguimos fazer na Saúde Coletiva e pensar estratégias para aperfeiçoá-la, tanto em seus característicos investimentos críticos sobre as ciências e técnicas da saúde, quanto em seus compromissos práticos e tarefas instrumentais. ${ }^{2}$

Com base nessa experiência, busco aqui recuperar um pouco do diálogo estabelecido entre a Saúde Coletiva, no processo de sua constituição como campo acadêmico, e a epistemologia histórica. Espero fornecer alguns indícios de como, na história de efeitos ${ }^{3}$ da tradição discursiva da epistemologia histórica francesa, contabiliza-se uma influente leitura de Georges Canguilhem (1904-1995) nesse campo, ainda que as contribuições desse filósofo e médico estejam longe de ter sido aí incorporadas de modo radical a conceitos e práticas. ${ }^{4}$

2 J. S. Paim e N. de Almeida Fo., A crise da saúde pública e a utopia da saúde coletiva (Salvador: Casa da Qualidade, 2000).

3 H. G. Gadamer, Verdade e método: traços fundamentais de uma hermenêutica filosófica (Petrópolis: Vozes, 2002).

4 K. R. Camargo Jr, "As armadilhas da 'concepção positiva de saúde"”, Physis: Revista de Saúde Coletiva, 17, 1 (1991): 6376. 
Nesse sentido, para que possa melhor ser compreendido, é preciso situar o leitor não familiarizado com a Saúde Coletiva. Esta tarefa não é exatamente simples, mas pode-se, de maneira bem sintética, defini-la como movimento de ideias e práticas que emerge no Brasil com intentos críticos e reconstrutivos desde a Saúde Pública e a Medicina Preventiva e Social nos anos 1970. Tendo como marco institucional a criação, em 1979, da Abrasco (então Associação Brasileira de Pós-Graduação em Saúde Coletiva, hoje simplesmente Associação Brasileira de Saúde Coletiva), esse campo se desenvolveu em estreita vinculação com o movimento social mais amplo que, envolvendo universidades, serviços, ativismo, conduziu ao processo chamado de Reforma Sanitária e à criação do Sistema Único de Saúde (SUS), em 1988. ${ }^{5}$ Em síntese, de forma integrada à luta contra a ditadura civil-militar de então e ao processo de redemocratização do país, o campo da Saúde Coletiva vem buscando construir saberes e práticas ativamente interessados nos determinantes socioculturais e econômicos dos processos de saúde-doença-cuidado, articulando suas construções científicas e proposições técnicas em saúde aos compromissos com a emancipação política dos sujeitos, a democracia e a justiça social.

A leitura de Georges Canguilhem, em especial seu texto de 1943, "O normal e o patológico”, "6 acompanhou o projeto acadêmico da Saúde Coletiva desde seu início, tornandose uma referência nas obras consideradas fundadoras do campo, ${ }^{7}$ em particular na tese de doutorado de Sérgio Arouca (1941-2003), "O dilema preventivista: contribuição para a compreensão e crítica da Medicina Preventiva", e a de Livre-Docência de Cecília Donnangelo (1940-1983), "Medicina e estrutura social (o campo da emergência da medicina comunitária.? O tipo de aproximação crítica às ciências médicas e a certas concepções e práticas da saúde desenvolvidas por Canguilhem mostrou-se bastante interessante na perspectiva dos impulsos reconstrutivos que animavam a Saúde Coletiva desde as suas origens. Ao longo dos cerca de 40 anos de existência desse campo, como era de se esperar, sua influência foi se diluindo e diversificando, mas nem por isso perdendo sua relevância, como pode ser atestado pelas referências já citadas. Entre os diversos destinos da leitura de sua obra, destacarei o aproveitamento realizado por professores do Departamento de Medicina Preventiva da Faculdade de Medicina Preventiva da Universidade de São Paulo, ao qual se encontra vinculada minha própria formação e produção na Saúde Coletiva. A construção do quadro da Teoria do Processo de Trabalho em Saúde ${ }^{10}$ se desdobrou em uma série de linhas e projetos de investigação, conformando o que pode ser considerado uma certa "escola de pensamento" dentre as diversas que compõem o amplo e plural campo da Saúde Coletiva brasileira. ${ }^{11}$ Penso que minha participação nesta vertente me permitirá identificar com certa clareza o significado de Canguilhem nesta trajetória e os desafios atuais que nos cobra essa presença.

\footnotetext{
${ }^{5}$ J. S. Paim, Reforma sanitária brasileira: contribuição para a compreensão e crítica (Salvador: EDUFBA/Rio de Janeiro: Editora Fiocruz, 2008).

${ }^{6}$ Georges Canguilhem, O normal e o patológico (Rio de Janeiro: Forense Universitária, 2015).

7 Cf. M. T. A. D. Coelho e F. N. Almeida, "Normal-patológico, saúde-doença: revisitando Canguilhem", Physis: Revista de Saúde Coletiva, 9, 1 (1999): 13-36. Esse artigo endossa a posição aqui defendida quanto à forte presença de Canguilhem (e Foucault) nas obras fundadoras da Saúde Coletiva. Contudo, embora não seja esse o foco do artigo, seus autores tendem a achar que tal importância teria sido um fenômeno quase fortuito, por uma equivocada identificação das obras desses filósofos a uma epistemologia de esquerda. Sem entrar no mérito do quanto as obras de Canguilhem tenham ou não sido vistas à época como "de esquerda" (e do quanto elas poderiam ou não receber essa classificação), não acompanho os autores nessa interpretação e penso que o diálogo com Canguilhem foi peça chave para criar o produtivo trânsito que a Saúde Coletiva logrou estabelecer entre o plano da política, dos movimentos sociais e dos serviços, de um lado, e da comunidade científica da medicina e da saúde pública, de outro. E isto menos por qualquer suposta articulação desses autores com algum quadro teórico de esquerda, mas porque forneceram recursos conceituais efetivos para relacionar o "interno" e o "externo" nas ciências da saúde, como procurarei demonstrar no artigo -

${ }^{8}$ S. Arouca, O dilema preventivista: contribuição para a compreensão e crítica da Medicina Preventiva (Tese de Doutorado, Unicamp, 1975).

${ }^{9}$ M. C. F. Donnangelo, Medicina e estrutura social: o campo de emergência da Medicina Comunitária (Tese de Livre-Docência USP, 1976), 95-124.

${ }^{10}$ R. B. Mendes-Gonçalves, Práticas de saúde e tecnologias: contribuição para a reflexão teórica (Brasília: OPS, 1988).

${ }^{11}$ R. B. Mendes-Gonçalves, Prefácio de J. R. C. M. Ayres, Epidemiologia e emancipação (São Paulo: Hucitec, 1995), 13-20.
} 


\section{Canguilhem e as origens da Saúde Coletiva}

As obras de Canguilhem começaram a ser divulgadas mais amplamente em português a partir do final dos anos 1970. Em 1978 foi divulgada a primeira edição de "O normal e o patológico". 12 "Ideologia e racionalidade nas ciências da vida foi o segundo texto a circular em português, mas publicado em Portugal, pelas Edições $70 .{ }^{13}$ Editado em 1981, a circulação desta obra foi mais tardia e menos expressiva na Saúde Coletiva, embora também lida por pesquisadores do campo, até porque alguns já acessavam a obra de Canguilhem no original em francês. ${ }^{14}$ Depois seguiu-se um longo interregno e só nos anos 2000 voltariam a circular edições de obras inéditas de Canguilhem em português, como os "Escritos sobre a medicina", 15 "Estudos de história e de filosofia das ciências: concernentes aos vivos e à vida"16 e "O conhecimento da vida". ${ }^{17}$

Cabe assinalar que, antes destas edições circularem, a revista Tempo Brasileiro já havia publicado, no início de 1972, um número inteiramente dedicado à epistemologia histórica francesa, ${ }^{18}$ que trazia duas traduções de textos de Bachelard, duas de Canguilhem, uma de Foucault e uma de Jacques-Alain Miller. Os textos de Canguilhem incluídos nessa coletânea foram também bastante citados na Saúde Coletiva, especialmente "O objeto da história das ciências". ${ }^{19}$ Este trabalho é citado por Sérgio Arouca em sua tese entre outras referências a obras de pensadores que estariam, segundo ele, favorecendo movimentos renovadores na Medicina Preventiva, por tornarem possível pensar as ciências sob uma nova perspectiva, mais adequada às referências críticas marxistas - adequação também valorizada por Althusser. ${ }^{20}$

Seguindo a Bachelard, a história epistemológica de Canguilhem rompia com o dogma do progresso contínuo e a imanência lógica do conhecimento, incorporava a materialidade técnica à compreensão das possibilidades heurísticas das ciências e, especialmente, considerava o aspecto ideológico elemento necessário para elucidar a construção de conceitos (embora considerando ideologia em um sentido em muitos aspectos diversos daquele que esta assumia na tradição marxista). Com isto, a obra de Canguilhem oferecia um suporte consistente para os impulsos renovadores de cunho político-emancipatório na saúde - e na Medicina Preventiva, em particular - sem que estes precisassem recusar, como irremediavelmente tecnocrática e opressora, a instrumentalidade das ciências médicas e sanitárias, constitutiva de sua identidade como campo. Sobre isso, diz-nos Arouca:

diante da realidade política latino-americana, em que o Estado tem frequentemente assumido total ou parcialmente o controle das ações de saúde, através dos diferentes sistemas previdenciários, leva, como tendência, a que a Medicina Preventiva se afaste, progressivamente, das suas relações com a sociedade civil para aproximar-se do Estado em sua dimensão tecnocrática.

Porém, no núcleo destas contradições, tem-se desenvolvido novas concepções do papel da Medicina Preventiva na transformação da teoria da Medicina,

\footnotetext{
${ }^{12}$ G. Canguilhem, O normal e o patológico (Rio de Janeiro: Forense Universitária, 1978).

${ }^{13} \mathrm{G}$. Canguilhem. Ideologia e racionalidade nas ciências da vida (Lisboa: Edições 70, 1981).

${ }^{14}$ R. L. Novaes. A saúde e os conceitos. São Paulo (Dissertação de Mestrado, Universidade de São Paulo, 1976); R. L. Novaes. Saúde e seu desenvolvimento histórico: aspectos críticos (São Paulo: Departamento de Medicina Preventiva da FMUSP/ Mimeo, 1973) \& H. M. D. Novaes, A puericultura em questão (Dissertação de Mestrado, São Paulo, 1979).

${ }^{15} \mathrm{G}$. Canguilhem. Escritos sobre a medicina (Rio de Janeiro: Forense-Universitária, 2005).

${ }_{16}$ G. Canguilhem, Estudos de história e de filosofia das ciências: concernentes aos vivos e à vida (Rio de Janeiro: Forense Universitária, 2012)

${ }_{17}$ G. Canguilhem, O conbecimento da vida (Rio de Janeiro: Forense Universitária, 2012)

${ }^{18}$ G. Bachelard, J. A. Miller, G. Canguilhem e M. Foucault, "Epistemologia", Revista Tempo Brasileiro, 28 (1972).

${ }^{19}$ G. Bachelard, J. A. Miller, Revista Tempo Brasileiro.

${ }^{20}$ L. Althusser, "Apresentação do posfácio de Pierre Macherey", em Georges Canguilhem, O normal e o patológico (Rio de Janeiro: Forense Universitária, 2015), 243-248.
} 
através de uma prática teórica específica, que consegue delimitar o ideológico no seu interior... tal possibilidade de prática teórica tem sido possível através da divulgação de trabalhos como os de Canguilhem, Bachelard, Althusser e Balibar, Foucault et alii., Fichant e Pecheux, Bernis, Labastida, Silmon, Piaget, Boltanski, Illich, Jantsche, Heckenhauser e outros, que num processo de abertura de novos horizontes dentro das ciências sociais tem fornecido novos instrumentais para a análise da Medicina. ${ }^{21}$

Vê-se a forte presença de Canguilhem não apenas por ser o primeiro da lista, mas também porque parte expressiva dos demais autores citados fora por ele direta ou indiretamente influenciado. Como destaca Foucault:

suprimam Canguilhem e vocês não compreenderão mais grande coisa de toda uma série de discussões que ocorreram entre os marxistas franceses; vocês não mais apreenderão o que há de específico em sociólogos como Bourdieu, Castel, Passeron, e que os marca tão intensamente no campo da sociologia; vocês negligenciarão todo um aspecto do trabalho teórico feito pelos psicanalistas, especialmente os lacanianos. Mais: em todo o debate de ideias que precedeu ou sucedeu o movimento de 1968, é fácil reencontrar o lugar daqueles que, direta ou indiretamente haviam sido formados por Canguilhem. ${ }^{22}$

Com efeito, a história epistemológica de Canguilhem, ao valorizar o erro, o acidente, o obstáculo como parte da construção dos conceitos científicos, permitia escapar da camisa de força do determinismo histórico, de matiz neo-hegeliano, fortalecendo novas perspectivas abertas no panorama filosófico pelas leituras fenomenológicas e estruturalistas que renovavam o marxismo. Ademais, suas pesquisas sobre as ciências da vida mostravam o caminho ao caminhar, abrindo possibilidades de se conceber e lidar com a inseparabilidade entre história e ciência, realizando na prática acadêmica concreta uma aproximação entre racionalismo e materialismo extremamente bem-vindas para a tradição marxista. ${ }^{23}$

É, porém, "Lo normal y lo patológico" 24 , edição argentina da obra então inédita no Brasil, que seria de fato diretamente influente na construção de "O dilema preventivista". Não tanto pelo método utilizado por Arouca, mais aparentado com a arqueologia do saber de Foucault e o estruturalismo marxista de Althusser, ${ }^{25}$ mas porque é ali que se encontra aquilo que me parece o argumento central e original de "O dilema" e que o tornaria canônico no campo da Saúde Coletiva: a questão da normatividade como chave da leitura dos processos de saúde-doença. Ao receber de Canguilhem a definição de saúde como capacidade de resposta às infidelidades do correr da vida que vão pondo à prova o valor prático de nossos processos físicos e mentais, abre-se o caminho para, de um lado, compreender os valores que estavam por trás de um certo conjunto de proposições tidas como promotoras, preservadoras ou recuperadoras do "normal", ou não patológico, como o discurso preventivista. De outro lado, as insuficiências percebidas nas práticas preventivistas tornavam possível questionar a eficácia normativa desses discursos, abrindo espaço para a crítica, por dentro do próprio

${ }^{21}$ S. Arouca, O dilema preventivista: contribuição para a compreensão e crítica da Medicina Preventiva (São Paulo: Ed. UNESP/Rio de Janeiro: Ed. FIOCRUZ, 2003), 142.

${ }^{22}$ M. Foucault, "A vida: a experiência e a ciência", em M. Foucault, Arqueologia das ciências e história dos sistemas de pensamento (Rio de Janeiro: Forense Universitária, 2008) 352-366 (Ditos e Escritos II), 353.

${ }_{23}$ D. Lecourt, "La historia epistemológica de Georges Canguilhem", em G. Canguilhem, Lo normal y lo patológico (Buenos Aires: Siglo XXI, 1971), VII-XXX. L. Althusser, "Apresentação do posfácio de Pierre Macherey"

${ }^{24}$ G. Canguilhem, Lo normal y lo patológico (Buenos Aires: Siglo XXI, 1971).

${ }^{25}$ E. D. Nunes, "Por uma arqueologia da Medicina Preventiva", em S. Arouca, O dilema preventivista: contribuição para a compreensão e crítica da Medicina Preventiva (São Paulo: Ed. UNESP/Rio de Janeiro: Ed. FIOCRUZ, 2003), 103-108. 
preventivismo, em meio às suas tendências conservadoras. É assim que Arouca pode identificar a estéril fatoração do social ao criticar o modelo de História Natural da Doença, de Leavell \& Clark, ${ }^{26}$ mas, ao mesmo tempo, enxergar no modelo ecológico de explicação causal, aí proposto, potências para reclamar uma abordagem da prevenção não restrita a uma leitura estritamente médica. É assim também que percebe o movimento da medicina comunitária como uma mudança normativa frente aos limites do preventivismo nos campos da Medicina e da Saúde Pública tradicionais e os perigos e oportunidades que aí se estabelecem e que nos acompanham até hoje no campo da Saúde Coletiva: quando buscamos estreitar as relações entre o campo institucional da saúde (formação de quadros, organização de serviços, ações oferecidas) e os processos sociopolíticos mais amplos, estamos abrindo o campo da saúde a novos sujeitos e práticas sociais, segundo novos padrões normativos, ou simplesmente medicalizando o social, escondendo em normalizações cientifica e tecnicamente conduzidas a imposição acrítica de um mesmo padrão de resposta normativa?

A centralidade deste argumento, e sua dupla face, de denúncia do caráter conservador e impermeável aos valores sociais emancipatórios da medicina e da saúde pública hegemônicas, de um lado, e, de outro lado, de aposta política em alternativas reconstrutivas emergentes de dentro da própria estrutura de discursos e práticas criticados, marcas da Saúde Coletiva, vão aparecer belamente ilustradas pouco tempo depois da defesa de tese de Arouca, ocorrida em julho de 1976. Em novembro do mesmo ano foi lançado o primeiro número da revista Saúde em Debate, publicada pelo CEBES - Centro de Brasileiro de Estudos de Saúde, organização cuja importância para a construção do campo da Saúde Coletiva é comparável à da Abrasco. Esta revista divulgou e catalisou intensamente a produção conceitual e política do Movimento da Reforma Sanitária e foi, assim, se constituindo em seu mais importante veículo de construção. Em seu primeiro número, entre outras importantes contribuições, Saúde em Debate publicou dois artigos, sequenciais na ordem em que estão dispostos na publicação - e, de fato, constituem contribuições interligadas - que bem podem ser lidas como uma proposta programática para a Saúde Coletiva. Sérgio Arouca publica “A História Natural das Doenças” e Anamaria Tambellini Arouca, então casada com Sérgio, assina com ele o segundo artigo chamado "Medicina de comunidade: implicações de uma teoria".

No primeiro artigo ${ }^{27}$, na verdade um excerto da tese (parte 2 do capítulo 4), vemos Arouca desconstruir o modelo de História Natural da Doença (HND) de Leavell e Clark. Destacado do conjunto da tese e do exame das contradições e aberturas próprias ao processo de construção do preventivismo, a retórica parece adquirir aqui um tom bem mais duro (porque unilateral) na crítica ao caráter conservador do modelo de HND. Aqui o enfatizado é o que eu resumiria como a "cegueira normativa" da medicina. O social trazido no modelo se colocaria apenas como um adjetivo e, enquanto tal, apenas se somaria a ele como um "mito", uma aparente reforma da medicina, mas que na verdade deixava intocado seu núcleo substantivo. E isso se daria, principalmente, por: 1) fatorar os aspectos sociais relacionados no modelo, subordinando-os à explicação dos processos de adoecimento como condições independentes entre si, como se não fossem partes de uma totalidade que os qualifica, integra e hierarquiza segundo modos de produção e reprodução material e culturalmente determinadas (um social naturalizado, portanto); 2) manter o padrão causalista de explicação dos fenômenos, repetindo o padrão das ciências naturais, apesar de expandi-lo para múltiplos fatores; usando o conceito de redes causais, o raciocínio linear e unidirecional das causas eficientes continuava, contudo, intacto; 3) manter no espaço tradicional das instituições de saúde o processo de trabalho a ser privilegiado na construção de respostas normativas às exigências de saúde, centralizadas na consulta médica, mantendo então os mesmos sujeitos e valores como detentores do monopólio das decisões normalizadoras sobre a saúde, a doença e o cuidado.

\footnotetext{
${ }^{26}$ H. R. Leavell \& E. G. Clark, Textbook of Preventive Medicine (New York: MacGraw-Hill, 1953).
}

${ }^{27}$ S. Arouca, "História Natural das Doenças", Saúde em Debate 1, 1 (1976): 15-19. 
Lido de forma isolada, esse artigo parece contraditório com o tipo de análise propiciada pela referência à obra de Canguilhem, que Arouca aproveitara de forma tão potente na tese. Há como que um determinismo, um destino imanentemente conservador do quadro da HND, do qual desaparecem as múltiplas vozes que vinham construído este quadro conceitual, entre as quais aquelas que, se ainda não eram capazes de transformar mais radicalmente os saberes da medicina e da saúde pública tradicionais, buscavam no conceito de prevenção/preventivismo respostas a problemas que, no mais fundamental, eram também preocupação do incipiente movimento da Reforma Sanitária: como integrar medicina com saúde pública, e como incorporar ao modo de conhecer e fazer de ambos o caráter social dos processos saúde-doença? Parece desaparecer também do excerto, fora do contexto da tese, o entendimento canguilhemiano do sentido de normatividade vital de que não se podem isentar quaisquer saberes sobre saúde, que permitiam entender a tensão que um quadro como o da HND provocava sobre as formas tradicionais da medicina e da saúde, favorecendo as apostas de renovação da então chamada medicina de comunidade.

No artigo seguinte, porém, passa-se desta postura de simples denúncia para uma abertura concreta a possibilidades de efetiva transformação das práticas:

Durante as últimas décadas, uma série de conceitos têm sido apresentados como solução para a chamada crise do setor saúde, tais como "medicina preventiva", "medicina compreensiva" e, mais recentemente, "medicina de comunidade". $\mathrm{Na}$ realidade, tais conceitos, surgidos de um mecanismo de adjetivação da medicina, não possuem atrás de si um quadro teórico que explique a realidade à qual se aplicam... a ausência de um quadro teórico que dê conta desta "crise" gera posições que, mantendo um distanciamento da teoria, constituem-se num conjunto desordenado de experiências empíricas que não colocam problemas ao conhecimento... porém o conjunto das experiências geradas por estas oposições pode ser um grande estímulo à produção teórica. ${ }^{29}$

E o autor que é, então, chamado a fornecer subsídios para construir os conceitos necessários à produção de respostas para as novas necessidades práticas do campo da saúde é ninguém mais ninguém menos que Georges Canguilhem:

Pretendemos neste artigo, a partir das teorias de Georges Canguilhem, verificar algumas das explicações possíveis em relação a este conjunto de práticas denominadas medicina de comunidade. ${ }^{30}$

Segue-se, então, uma resenha das contribuições de Canguilhem. Embora não haja referências bibliográficas no artigo, o trabalho resenhado é, basicamente, "Lo normal y lo patológico". Na cuidadosa resenha, ainda que sintética, o que é destacado pelo casal Arouca é a reconstrução do conceito de saúde e doença levada a cabo por Canguilhem a partir do seu conceito central de normatividade vital e sua relação com os "modos de andar a vida" "31. Isto é,

\footnotetext{
${ }^{29}$ A. T. Arouca e S. Arouca, "Medicina de comunidade: implicações de uma teoria", Saúde em Debate 1, 1 (1976): 20-23, 20.

${ }^{30}$ A. T. Arouca e S. Arouca, "Medicina de comunidade: implicações de uma teoria", 20.

${ }^{31}$ Uma curiosidade é que "modos de andar a vida", esta bela e eloquente expressão, até hoje amplamente utilizada na Saúde Coletiva brasileira, não é encontrada na edição em português de "O normal e o patológico". Ela foi uma tradução livre de "modos de andar de la vida", originária da edição argentina de 1971. A tradução brasileira do original "allures de la vie" (G. Canguilhem, Le normal et le patologique (Paris: PUF, 1966)) utiliza expressões diversas ao longo do texto, como "modos da vida", "modos de vida", "modos de ser da vida", "ritmos da vida" e
} 
a saúde passa a ser entendida como resposta satisfatória, na experiência vivida, de nossas capacidades de responder às "infidelidades" que ameaçam nossa integridade e bem-estar, qualificando, assim, saúde e doença como polaridades valorativas (positiva ou negativa) relacionadas à nossa capacidade de responder (ou não) às exigências normativas, assim como de produzir normas que atendam às nossas expectativas e necessidades como viventes. Nesta mesma perspectiva, e apoiando-se na crítica de Canguilhem às pretensões cientificistas de definir fisiologicamente a doença pelo valor negativo de fenômenos para o funcionamento ótimo da totalidade orgânica ("Não se ditam cientificamente normas à vida"), sugerem também a necessidade de reconstruir as relações entre ciências e técnicas na medicina. Propõem que se resgate a precedência prática destas últimas, assim como rever os espaços e recursos das práticas de saúde, de modo a tornar possível às pessoas "apropriar-se" de suas lógicas e recursos para seu próprio benefício, ao invés de serem expropriados das suas experiências e interesses em saúde pelo "mundo insólito" desses ambientes e procedimentos técnicos. E, embora ressaltando que esta é apenas uma entre outras possíveis contribuições teóricas inovadoras em torno à medicina de comunidade, concluem:

Portanto, devemos, a partir de Canguilhem:

- Libertar a vida para que ela, através da experiência dos sujeitos concretos, pergunte à ciência sobre a experiência...

- Libertar o homem em sua "experiência", o que significa fornecer-lhe os meios para compreender e controlar o seu "modo de andar a vida... ${ }^{32}$

\section{Canguilhem e o Departamento de Medicina Preventiva da Faculdade de Medicina da Universidade de São Paulo}

Em meados dos anos 1970, perseguido politicamente, o grupo de professores e estudantes catalisado por Arouca na Unicamp começa a se dispersar. ${ }^{33}$ Este grupo era composto por nomes que viriam a ter grande relevância para a saúde no país, além do próprio casal Arouca, como David Capistrano Costa Filho (1948-2000) e Eleutério Rodriguez Neto (1946-2013). Arouca se transferiu em 1976 para a Escola Nacional de Saúde Pública. O Departamento de Medicina Preventiva e seu programa de pós-graduação, que também desempenhavam o papel de um importante centro de atração e irradiação do pensamento crítico da nascente Saúde Coletiva, recebeu também egressos e simpatizantes desse grupo, por exemplo, Eleutério Rodriguez Neto, Ricardo Lafetá Novaes (1945-1998) e Hillegonda Maria Dutilh Novaes. Aí já se encontravam Cecília Donnangelo e Guilherme Rodrigues da Silva (1928-2006), duas das maiores lideranças políticas e intelectuais na construção do campo. Também nesse ambiente vai se fazer notar a forte influência da obra de Canguilhem.

Ricardo Lafetá Novaes foi um dos que, em estreita relação com Arouca e seu grupo, e compartilhando com esses o interesse por refletir criticamente sobre os conceitos que embasavam as práticas de saúde, desenvolveu na Medicina Preventiva da USP, sob orientação do Prof. Guilherme Rodrigues da Silva, uma dissertação de mestrado onde a influência de

“comportamentos da vida" - cf. Georges Canguilhem, O normal e o patológico, 2015. Essa tradução mostra-se, porém, problemática, como se vê no importante parágrafo em que Canguilhem define o conteúdo conceitual que pretende dar à expressão. Traduz-se "allures inédites de la vie" por "comportamentos inéditos da vida", quando no parágrafo imediatamente acima, o autor diz preferir esta expressão ("allure", ou passo, andamento, ou "modos de andar a vida") ao uso do termo comportamento "... para fazer sentir melhor que a vida é polaridade dinâmica". Nesse mesmo parágrafo, a tradução incorre em similar empobrecimento da intenção conceitual de Canguilhem ao traduzir allures por ritmos: "Parece-nos que, definindo a fisiologia como ciência dos ritmos estabilizados da vida, respondemos a quase todas as exigências oriundas de nossas posições anteriores" c $f$. Georges Canguilhem, $O$ normal $e$ o patológico, 2015, 146). Já inseri a referência em nota na página 3 acima.

${ }^{32}$ A. T. Arouca e S. Arouca, "Medicina de comunidade: implicações de uma teoria", 23.

${ }^{33}$ Comissão da Verdade e Memória Otávio Ianni (Relatório Final, Unicamp: Universidade Estadual de Campinas, 2015). 
Canguilhem é marcante. "A saúde e os conceitos",34 é contemporâneo dos trabalhos dos Arouca, acima citados, e se parece com eles. Desde a referência metodológica centrada em Althusser, até a defesa da necessidade de reconstrução conceitual para efetivar as mudanças apontadas pelas propostas de reforma da atenção e do ensino médicos, mas, especialmente, pelo apoio na epistemologia histórica de Canguilhem e no potencial reconstrutivo do seu conceito de normatividade em saúde, esse estudo de Novaes soa quase como uma continuidade do investimento teórico proposto no artigo da Saúde em Debate. ${ }^{35}$

Maria Novaes também dá continuidade ao diálogo com Canguilhem, mas, diversamente de Lafetá, interessa-se mais pelo historiador das ciências do que pelo filósofo embora, por força do próprio referencial da epistemologia histórica, sua recuperação da história da puericultura ${ }^{36}$ foi também guiada pela reflexão sobre as bases epistemológicas das ciências médicas, ao mesmo tempo em que as discussões sobre esse conhecimento se apoiaram nas informações históricas que recolheu. Em seu estudo, o recurso a Canguilhem, embora também se apoie na questão da normatividade, que, como vimos, foi a ponte que ligou os territórios da Saúde Coletiva à obra de Canguilhem, foi fundamentalmente para caracterizar a particularidade do objeto da história das ciências e aproveitar os próprios desenvolvimentos desse autor sobre a história das ciências médicas. Para isso, além de "O normal e o patológico", recorreu ao clássico texto "O objeto da história das ciências", 37 e a "Ideologie et racionalité", 38 em sua versão original francesa.

Do trabalho que Cecília Donnangelo vinha desenvolvendo no Departamento derivouse também um importante aproveitamento das contribuições da epistemologia histórica na Saúde Coletiva que me interessa aqui examinar em particular, posto que produziu uma inflexão bastante original, e que resultou em uma linha de investigações até hoje em curso no Departamento e influente fora dele também.

Em "Saúde e sociedade", 39 considerada, junto com "O dilema preventivista", obra fundadora da Saúde Coletiva, conforme já assinalado, encontramos Canguilhem logo nos primeiros parágrafos. E aqui, como nos trabalhos acima citados, o recurso ao filósofo deve-se à sua concepção de normatividade da vida e o deslocamento que impõe às concepções tradicionais de saúde e doença - e suas consequências sobre o pensar as relações entre fisiologia e patologia e, especialmente, entre ciência, técnica e prática.

A Clínica é inseparável da terapêutica e esta é uma técnica de instauração e restauração do normal cujo objetivo, a saber a satisfação subjetiva de uma norma que está instaurada, escapa à jurisdição do saber objetivo. Não se ditam normas científicas à vida. (...) A própria vida (...) é quem introduz na consciência humana as categorias de saúde e enfermidade. Essas categorias são biologicamente técnicas e subjetivas e não biologicamente científicas e objetivas. 40

Donnangelo segue dialogando com "O normal e o patológico" por todo o primeiro capítulo, "Medicina: prática técnica - prática social", da primeira parte do trabalho, denominada "Medicina e estrutura social". Esta obra é fundamental para a construção daquilo

\footnotetext{
${ }^{34}$ R. L. Novaes. A saúde e os conceitos. São Paulo.

${ }_{35}$ A. T. Arouca e S. Arouca, "Medicina de comunidade: implicações de uma teoria", 23.

${ }^{36}$ H. M. D. Novaes, A puericultura em questão.

${ }_{37}^{37}$ G. Bachelard, J. A. Miller, Revista Tempo Brasileiro.

${ }^{38} \mathrm{G}$. Canguilhem. Ideologia e racionalidade nas ciências da vida.

${ }^{39}$ M. C. F Donnangelo e L. Pereira, Saúde e sociedade (São Paulo: Duas Cidades, 1976).

${ }^{40}$ M. C. F. Donnangelo e L. Pereira, Saúde e sociedade, 16-17.
} 
que viria ser a marca principal da contribuição da autora para o campo da Saúde Coletiva: a necessidade de se explorar a consubstancialidade técnico-social dos saberes e práticas de saúde. Foi por essa via que, mais uma vez, Canguilhem foi chamado a sustentar uma direção programática para a reconstrução das práticas de saúde almejadas pelo movimento sanitário brasileiro - e também aqui motivada pela crise da medicina e pela crítica às insuficiências dos modelos de reforma propostos pelo preventivismo e pela medicina de comunidade, ou medicina comunitária, como a chama Donnangelo, alinhando-se àquelas já realizadas por Arouca ${ }^{41} \mathrm{e}$ Guilherme Rodrigues da Silva. ${ }^{42}$ Ao apontar a prioridade ontológica do patológico sobre o fisiológico, entendendo-se aquele como um obstáculo experimentado por dado modo de andar a vida, reclamando novas normas de regulação a serem produzidas para o corpo ou para o seu meio, Canguilhem deixa claro que as leituras sobre corpos e meios efetuados pelas ciências da vida e da saúde, segundo os interesses normativos que irão produzir técnicas de intervenção normalizadora, não são expressões objetivas imanentes de uma natureza desvelada pelo conhecimento metódico das ciências, mas, antes, revelam a precedência e ascendência dos valores sobre a objetividade científica e a relação destes valores com necessidades e possibilidades inscritas na concretude das experiências de estar vivendo.

Esta construção, como já apontado, permitia estabelecer um bem-sucedido diálogo com as posições do materialismo histórico, tão importante no ambiente acadêmico da Saúde Coletiva, uma vez que fornecia elementos que não apenas davam densidade conceitual à denúncia do mito da neutralidade axiológica das ciências e das técnicas, como criavam a possibilidade de um trânsito teórico-metodológico entre a investigação dos aspectos sociopolíticos relacionados às experiências concretas de saúde, doença e cuidado e o plano epistemológico dos saberes e práticas da medicina.

Assim, dialogando com diferentes interesses e autores, dentro do marxismo e fora dele (destaque-se aí a importância de Foucault), foram derivadas diversas maneiras de aproveitamento da obra de Canguilhem no Departamento de Medicina Preventiva. Dialogando especialmente com Althusser, por exemplo, Novaes ressaltou especialmente o componente ideológico e a denúncia da intransparência dos sentidos normativos das práticas de exercício e ensino da medicina, por força de mecanismos estruturais de dominação de classe:

Pensamos que a saúde é processo orgânico sobredeterminado por normas vitais superiores que permitem ao organismo ser normativo, processo que é novamente sobredeterminado pois que o VALOR dominante é decorrente das representações e exigências da estrutura social que, dadas relações de produção, institui as classes e a sua luta. Saúde e doença são assim muito mais valores sociais historicamente colocados do que a simples expressão da situação biológica do organismo (em geral) em um meio dado. ${ }^{43}$

Donnangelo, em diálogo também com autores estruturalistas, mas buscando especialmente em Gramsci oportunidades de pensar os aspectos estruturados e estruturantes das práticas de saúde nas formações sociais em termos dos conflitos e contradições entre projetos (e sujeitos) sociais (hegemônicos e contra-hegemônicos), colocará o foco de suas análises muito mais sobre a ação política do que sobre o aspecto da dominação ideológica propriamente dita. Na primeira e mais importante parte de seu trabalho, a autora traça um panorama da conformação das práticas de saúde nas formações sociais capitalistas, sintetizadas no excerto abaixo:

\footnotetext{
${ }^{41} \mathrm{~S}$. Arouca, O dilema preventivista: contribuição para a compreensão e crítica da Medicina Preventiva.

${ }^{42}$ G. R. Silva, "Origens da Medicina Preventiva como disciplina do ensino médico", Rev. Hosp. Clin. Fac. Med. S. Paulo, 28 (1973): 91-96.

${ }^{43}$ R. L. Novaes. A saúde e os conceitos. São Paulo.
} 
A redefinição da medicina como prática social aparece já marcadamente no século XVIII, através de sua extensão institucionalizada para o âmbito de toda a sociedade, permeando o processo político e econômico de forma peculiar. Não é o cuidado médico que então se generaliza e sim o que se poderia considerar, de maneira aproximada, uma extensão do campo de normatividade da medicina através da definição de novos princípios referentes ao significado da saúde e da interferência médica na organização da população e de suas condições gerais de vida. ${ }^{44}$

Essa "medicalização" da vida social torna-se, então, a base da sua análise crítica sobre as relações entre saúde e sociedade e a consubstancialidade técnico-social das práticas de saúde. Mas sua análise da medicalização nos moldes operados pela medicina comunitária irá destacar não mais o sentido de "controle" da força de trabalho, como nos primórdios do processo de transformação capitalista das sociedades ocidentais, e sim a extensão (a baixo custo) do consumo de serviços de saúde, consolidando a prática médica como trabalho social e legitimando politicamente o padrão normativo (intransparente) reiterado pelas ciências e técnicas da medicina.

Com isso, Saúde e Sociedade não apenas produz um arcabouço teórico para análise sobre a medicina comunitária, mas constrói balizamentos conceituais para uma sociologia da saúde de maneira mais geral. ${ }^{45} \mathrm{E}$, embora extrapole as possibilidades de tratamento no espaço deste artigo, não será difícil imaginar a riqueza de possibilidades que se abriram, então, ao pensamento crítico no campo da Saúde Coletiva pela combinação da abertura à consubstancialidade técnico-social das práticas de saúde e possibilidade de levar sua investigação à intimidade da conformação das ciências e técnicas que embasam essas práticas pelo produtivo diálogo estabelecido com a epistemologia histórica. O mais significativo desses tratamentos, ao menos aquele que se desdobrou na produção dos interlocutores mais próximos de Cecília, vai se debruçar sobre a questão da medicina como trabalho, entendido não na estrita condição de uma atividade produtiva "infraestrutural" das sociedades capitalistas, mas como prática de sujeitos (os médicos) vinculados de modos contraditórios (como dominados e dominantes) ao manejo tecnocientífico de normatividades postas para o controle da saúde no contexto de modos de reprodução social historicamente constituídos. ${ }^{46}$ Não comentaremos toda essa extensa e rica produção em seu conjunto. Vou enfocar apenas a vertente teórica em que mais fortemente se estreitou o diálogo com a epistemologia histórica.

\section{Canguilhem e a Teoria do Processo de Trabalho em Saúde}

Ricardo Bruno Mendes Gonçalves (1946-1996), mais próximo colaborador de Cecília Donnangelo, defendeu seu mestrado, "Medicina e história: raízes sociais do trabalho médico" pouco tempo após a Livre-Docência de Donnangelo. Seu trabalho é tão vinculado ao dela que até parece complementá-lo, no sentido cobrado por Luiz Pereira (1933-1985) em sua arguição à

\footnotetext{
44 M. C. F. Donnangelo e L. Pereira, Saúde e sociedade, 47.

${ }^{45}$ L. Pereira, "Capitalismo e saúde", em M. C. F. Donnangelo \& L. Pereira, Saúde e sociedade (São Paulo: Duas Cidades, 1976), 95-124.

${ }^{46}$ R. B. Mendes-Gonçalves, Medicina e história: raízes sociais do trabalho médico (Dissertação de Mestrado, Universidade de São Paulo, 1979); R. B. Mendes-Gonçalves, Tecnologia e organização social das práticas de saúde: características tecnológicas do processo de trabalho na rede estadual de centros de saúde. São Paulo (Dissertação de Doutorado, Universidade de São Paulo, 1986); L. B. Schraiber, Contribuição ao estudo da educação médica (Dissertação de mestrado, Universidade de São Paulo, 1980); L. B. Schraiber, Medicina Liberal e Incorporação de Tecnologia: as transformações históricas na autonomia profissional dos médicos em São Paulo (Tese de doutorado - Universidade de São Paulo, 1989).
} 
autora: "Justamente por ter a Autora apreendido as determinações infra-estruturais da prática médica pelas funções desta, deixa uma lacuna em sua tese no que se refere a tais determinações: deixa de pensar a prática médica como trabalho". ${ }^{47}$

Foi esse, como dissemos acima, o caminho tomado por Ricardo Bruno em seu mestrado. Não cabe aqui explorar em detalhe os conteúdos desta importante obra, mas vou apenas destacar, brevemente, o modo como ela, embasando o que viria a ser sua Teoria do Processo de Trabalho em Saúde (TPTS), permitiu continuar o diálogo de Canguilhem com a Saúde Coletiva. Nesse sentido, é importante apontar que, na perspectiva conceitual de "Medicina e história", o materialismo e a história passaram a ser não apenas formas de expressar uma tomada de posição política, de denúncia crítica dos sentidos conservadores das práticas de saúde, mas configurou positivamente possibilidades de pesquisa teórica e aplicada de um caráter que podemos chamar de reconstrutivo. Talvez pela influência gramsciana, Ricardo Bruno mostrou-se especialmente sensível ao devir histórico e ao papel dos sujeitos e suas interações, permitindo apostar nas possibilidades reconstrutivas pelo interior mesmo das práticas de saúde. Esta perspectiva é aberta, em primeiro lugar, pela caracterização, em "Medicina e história", da dupla posição dos médicos nas sociedades capitalistas: de um lado, membros de uma elite intelectual que formula os projetos sociais hegemônicos, baseados na legitimidade e poder prático das ciências médicas, de outro, trabalhadores que produzem serviços e, enquanto tal, são dominados não apenas pelas relações de produção que progressivamente definem seus modos de trabalho e de vida, mas também pelo progressivo poder da tecnologia em determinar o sentido e o valor do seu conhecimento e de determinar seu lugar nos processos (parcelares) de trabalho em saúde. É justamente essa inserção contraditória que torna possível, segundo Ricardo, enxergar as potencialidades emancipadoras de uma prática teórica que se dedique a explorar o modo como as tecnologias se relacionam com as ciências da saúde e seus sujeitos. Apostar na investigação empírica e reflexão crítica acerca das tecnologias do trabalho médico (incluindo sua relação com as ciências) pode, segundo esse autor, produzir tensões e transformar posições de sujeitos, relações de poder e, portanto, valores e normatividades orientadores de nossas práticas de saúde. 48

Um dos produtos desse fértil diálogo entre a compreensão da prática médica como trabalho e a epistemologia histórica de Canguilhem, iniciado com "Medicina e História", vai aparecer com toda a força em um trabalho originalmente publicado em 1985 e reeditado em 1990, ${ }^{49}$ de forte impacto na Saúde Coletiva. Nesse estudo é examinada a relação da ciência epidemiológica com a prática médica, desenvolvendo a tese de que, no trabalho concretamente operado no contexto do desenvolvimento histórico da clínica moderna, ao longo dos séculos XIX e XX, as perspectivas normativas das quais se originou este saber são subsumidas a uma perspectiva do trabalho médico. O Canguilhem de "O normal e o patológico" é central na construção do referencial teórico do texto (pgs. 41-53), principalmente para compreender como a normatividade higienista na origem da epidemiologia, que ambicionava o manejo dos determinantes sociais dos processos de adoecimento, foi subsumida como trabalho concretamente operado na medicina ao manejo individualizado desse social, tal como expresso no modelo de História Natural da Doença.

Em seu doutorado, ${ }^{50}$ Ricardo deu sequência a seu empreendimento teórico adensando e amadurecendo seu quadro conceitual e aplicando-o, então, a uma pesquisa empírica acerca

\footnotetext{
${ }^{47}$ M. C. F. Donnangelo e L. Pereira, Saúde e sociedade, 111.

${ }^{48}$ J. R. C. M. Ayres, "Ricardo Bruno: história, processos sociais e práticas de saúde", Ciência e Saúde Coletiva, 20, 3 (2015): 905-912.

49 R. B. Mendes-Gonçalves, "Reflexão sobre a articulação entre a investigação epidemiológica e a prática médica, a propósito das doenças crônicas e degenerativas”, em D. C. Costa, Epidemiologia: teoria e objeto (São Paulo: Hucitec/Rio de Janeiro: Abrasco, 1990), 39-86.

${ }^{50}$ R. B. Mendes-Gonçalves, Tecnologia e organização social das práticas de saúde: características tecnológicas do processo de trabalbo na rede estadual de centros de saúde. São Paulo (Dissertação de Doutorado, Universidade de São Paulo, 1986).
} 
dos processos de trabalho concretamente operados em Centros de Saúde da rede de São Paulo. A dívida deste empreendimento com a arquitetura conceitual que viemos discutindo é explícita nas referências bibliográficas e aparece sintetizada nos excertos abaixo:

[a prática médica] é trabalho, por fim, porque visa a obtenção de determinados efeitos, busca alterar um estado de coisas estabelecido como carecimento, e ao fazê-lo vale-se das concepções cientificamente elaboradas sobre o corpo para lidar com algo que escapa aos limites do corpo, ainda que possa ser assim apreendido: o patológico, enquanto expressão de uma normatividade específica. (...) ... as análises de Canguilhem e Donnangelo permitem compreender... que o corpo anátomo-fisiológico já não se define como normal ou patológico senão tomando já como referência essas estruturas de normatividade extra-biológicas e que, por consequência, a normatividade está imediatamente contida no objeto de trabalho do médico. ${ }^{51}$

Entendidas como trabalho, sustenta, as práticas de saúde admitem ser analisadas como conjunto de conhecimentos do tipo científico ("saber que"), saberes técnico-operatórios ("saber como") e uma correspondente instrumentalidade material, todos integrados e qualificados por normatividades relativas a determinados modos de andar a vida e configurados enquanto tal (trabalho em saúde) apenas nas formas concretas de sua operação. Por conseguinte, toda desconstrução crítica das práticas de saúde encontrará um poderoso recurso na apreensão dos sentidos efetivamente assumidos por suas ciências no modo como se articulam com o trabalho concretamente operado em seu campo de normatividade. Na mesma direção, mas em sentido inverso, podemos assumir que a reconstrução das práticas de saúde depende de conseguirmos criar condições políticas para que novos horizontes de normatividade possam ser socialmente reconhecidos e validados e (e porquanto) o valor das ciências (e técnicas) que os podem fazer valer seja concretamente experimentado.

Em razão da fragilização de sua saúde e sua morte precoce, Ricardo Bruno não teve oportunidade de dar maiores desenvolvimentos teóricos a esse quadro, exceto em algumas produções mais pontuais, como sua discussão sobre necessidades de saúde ${ }^{52}$ e comentários a partir de trabalhos de alunos seus. ${ }^{53}$ Contudo Lilia Schraiber, Maria Ines Baptistella Nemes e outros colaboradores e alunos, muitos e em diversas partes do país, deram seguimento a programas de investigação derivados da TPTS ou em diálogo com essa produção - a começar pela própria experimentação de novos arranjos tecnológicos para as práticas da atenção primária à saúde em uma unidade básica, o Centro de Saúde Escola Samuel B. Pessoa. ${ }^{54}$

Em diversas dessas produções o pensamento de Canguilhem segue sendo, direta ou indiretamente, uma referência relevante e apontando, nos seus aproveitamentos e omissões, as exigências de renovação crítica a que um trabalho intelectual vigoroso e rigoroso como o seu está sempre convidando.

${ }^{51}$ R. B. Mendes-Gonçalves, Tecnologia e organização social das práticas de saúde: características tecnológicas do processo de trabalho na rede estadual de centros de saúde. São Paulo, 66-68.

52 R. B. Mendes-Gonçalves, Práticas de saúde: processos de trabalbo e necessidades (São Paulo: CEFOR, 1992) Cadernos CEFOR, Textos 1.

${ }^{53}$ R. B. Mendes-Gonçalves, Prefácio em J. R. C. M. Ayres, Epidemiologia e emancipação (São Paulo: Hucitec, 1995ª),13-20 \& R. B. Mendes-Gonçalves, "Seres humanos e práticas de saúde: comentários sobre "razão e planejamento" em Gallo E (org.), Razão e planejamento: reflexões sobre política, estratégia e liberdade (São Paulo: Hucitec/Rio de Janeiro: Abrasco, 1995b), 13-31.

${ }^{54}$ L. B. Schraiber (org.), Programação em saúde hoje (São Paulo: Hucitec, 1990) \& L. B. Schraiber, M. I. B. Nemes, R. B. Mendes-Gonçalves (orgs.) Saúde do adulto: ações e programas na unidade básica (São Paulo: Hucitec, 1996). 


\section{Canguilhem e a Saúde Coletiva hoje, algumas reflexões finais}

A difusão da obra de Canguilhem ampliou-se na Saúde Coletiva (e deve ampliar-se mais, com a recente publicação de novas obras suas em português), a tal ponto que seria difícil avaliar os modos de seu aproveitamento na produção atual desse campo sem um trabalhoso inventário, do que não se trata aqui. Algumas publicações dos últimos 20 anos em periódicos do campo já nos dão indícios, contudo, da continuidade do diálogo com esse pensador em diversos centros acadêmicos do país e mesmo fora dele ${ }^{55}$ (Camargo Jr., 2007). Também é difícil julgar, frente a essa dispersão e crescimento da produção do campo da Saúde Coletiva, se o diálogo com essa obra continua exercendo o mesmo efeito de enraizar na experiência vivida, por intermédio da reflexão sobre a questão da normatividade, as reflexões sobre as ciências da saúde e as tecnologias a elas relacionadas. O que claramente parece não haver hoje é um recurso a Canguilhem como base conceitual para uma plataforma político-científica de natureza programática para o campo da Saúde Coletiva como um todo, como nos anos 1970 (mas existe alguma?!). Nesse sentido, talvez seja necessário realizar investigações mais regionais, não apenas no sentido geográfico, mas especialmente no sentido de regiões de aplicação da racionalidade da Saúde Coletiva, para avaliar a penetração e a fecundidade desse diálogo. Estará sua obra atuando efetivamente na construção de conceitos na Saúde Coletiva?

Vou procurar responder a esta questão a partir da reflexão sobre alguns desdobramentos das contribuições de Canguilhem no âmbito da Teoria do Processo de Trabalho em Saúde na minha própria produção.. Tal exame, a ser feito a seguir, não quer pretender qualquer tipo de representatividade ampliada, mas poderá ser útil para apontar algumas possibilidades e desafios para a continuidade desse produtivo diálogo com o pensador da normatividade vital.

Partindo da consubstancialidade técnico-social das práticas de saúde (Donnangelo) e da relação entre conhecimento e processos de trabalho na compreensão da historicidade e configuração epistemológica das ciências da saúde (Mendes Gonçalves), desenvolvi duas vertentes de produção acadêmica nas quais vejo claramente as contribuições de Canguilhem. Em primeiro lugar, na busca da compreensão da gênese e fundamentos epistemológicos da epidemiologia, saber estratégico na operação da normatividade sócio-sanitária nos processos de trabalho em saúde. Em segundo lugar, na crítica ao paroxismo tecnicista das práticas de atenção à saúde.

Já no modo como denominei a primeira vertente, fica explícita a influência de Canguilhem: crítica histórico-epistemológica da epidemiologia, trabalho de mestrado desenvolvido entre 1986 e $1991 .{ }^{56}$ De fato, se com Ricardo Bruno fui despertado para estudar essa ciência tão relevante para o projeto da Saúde Coletiva a partir da perspectiva dos processos de trabalho em saúde (no caso, suas relações com as práticas de saúde pública), foi com a leitura de Canguilhem que encontrei um caminho coerente para fazê-lo. Isto porque, por mais que uma

\footnotetext{
${ }_{5}^{5}$ A. Martins, "Novos paradigmas e saúde”, Physis: Revista de Saúde Coletiva 9, 1 (1999): 83-112 ; M. T. A. D Coelho e N. Almeida Fo., "Conceitos de saúde em discursos contemporâneos de referência científica", História, Ciências, Saúde Manguinhos, 9, 2 (2002): 315-33; J. C. R. S. Soares e K. R. de Camargo Jr, "A autonomia do paciente no processo terapêutico como valor para a saúde", Interface - Comunic., Saúde, Educ, 11, 21 (2007): 65-78 ; J. R. C. M. Ayres, "Uma concepção hermenêutica de saúde", Physis: Revista de Saúde Coletiva, 17, 1 (2007): 43-62 ; K. R. de Camargo Jr., "As armadilhas da concepção positiva de saúde”, Physis: Revista de Saúde Coletiva, 17, 1 (2007), 63-76; R. F. Puttini e A. Pereira Jr. "Além do mecanicismo e do vitalismo: a 'normatividade da vida' em Georges Canguilhem", Physis: Revista de Saúde Coletiva, 17, 3 (2007): 451-464 ; C. Resende, "O que pode um corpo? O método Angel Vianna de conscientização do movimento como um instrumento terapêutico", Physis: Revista de Saúde Coletiva, 18, 3 (2008): 563 574 ; D. Czeresnia, "Canguilhem e o caráter filosófico das ciências da vida", Physis: Revista de Saúde Coletiva, 20, 3 (2010): 709-727; S. Caponi, "Georges Canguilhem: del cuerpo subjetivo a la localización cerebral", Salud Colectiva, 6 , 2 (2010):149-161; A. Ostachuck, "La vida como actividad normativa y auto-realización: debate en torno al concepto de normatividad biológica en Goldstein y Canguilhem”, História, Ciências, Saúde - Manguinhos, 22, 4 (2015): 1199-1214.

${ }^{56}$ J. R. C. M. Ayres, Epidemiologia e emancipação (São Paulo: Hucitec/Rio de Janeiro: Abrasco, 1995).
} 
ciência esteja implicada em processos concretos de trabalho, há diferenças importantes, claro, entre o modo como ela se deixa apreender como parte de uma tecnologia e os processos que caracterizam o momento de sua produção como conhecimento. Os interesses e compromissos "internos" e "externos" da comunidade de cientistas que produziam a epidemiologia, a materialidade técnica que promovia ou detinha seus caminhos, o grau e tipo de desenvolvimento da racionalidade que ela aplicava a seus problemas de investigação, e o contexto sociopolítico mais amplo, que sancionava ou não suas construções, tudo isso reclamava um referencial que trouxesse para o estudo a perspectiva não apenas de uma filosofia das ciências, uma epistemologia, mas também, para além dela, e junto dela, uma sociologia das ciências.

Entre os clássicos que de alguma forma traziam já essas perspectivas em diálogo, Thomas Kuhn ${ }^{57}$ parecia iluminador com seu conceito de paradigma. "Estruturas paradigmáticas", modo como incorporei as contribuições desse autor ao meu próprio quadro conceitual, permitiriam explorar racionalidades, instituições e recursos que, do interior da comunidade científica da saúde, construíram a ciência epidemiológica que dialogava (ou não) com as exigências sócio-sanitárias que se constituíam como trabalho social em diferentes momentos históricos. Porém Canguilhem já nos ensinara que as ciências da saúde eram, muito mais imediatamente que outras ciências, a própria vida humana estabelecendo para si e seu meio os padrões normativos capazes de satisfazer suas necessidades e experimentar suas possibilidades. Era preciso, então, uma certa "hibridização" do quadro kuhniano com uma reflexão acerca do problema do valor sócio-vital que esclarecia a construção dos conceitos esse ponto de partida da história epistemológica de Canguilhem. Foi assim que cheguei à formulação das estruturas normativo-paradigmáticas para empreender meu estudo sobre a epistemologia da epidemiologia - a que chamei de crítica histórico-epistemológica para destacar um valor normativo que eu próprio estava perseguindo com meu estudo, basicamente o interesse reconstrutivo do campo da Saúde Coletiva.

Se o diálogo com o conceito de paradigma buscou suprir um certo "deficit sociológico", frequentemente apontado como limite do método de Canguilhem, ${ }^{58}$ da mesma forma que, por outro lado, Canguilhem permitiu trazer para a análise a questão do sentido normativo das ciências da saúde, de que carecia o quadro kuhniano, havia ainda um outro desafio a enfrentar na crítica histórico-epistemológica. Ele diz respeito às dificuldades da análise das estruturas de racionalidade para dar conta do sentido da ação política que as constrói e reconstrói na perseguição das exigências normativas a que respondem. Para isso recorreu-se naquele trabalho ${ }^{59}$ às noções de projeto antropoemancipador e projeto tecnoconservador (tributárias da tradição fenomenológico-existencialista), com relativo sucesso naquele contexto, ${ }^{60}$ mas a questão do sentido da ação sempre se recolocará como desafio para a epistemologia histórica na medida em que se vão transformando não apenas os campos de aplicação das ciências, mas seus próprios interesses normativos.

Essa linha de investigação seguiu adiante, focalizando de modo mais aprofundado um dos conceitos desenvolvidos pela epidemiologia, justamente aquele que permitiu que seu discurso ultrapassasse o limiar de formalização, ${ }^{61}$ alinhando-se entre as ciências " hard" da saúde no século XX: o conceito de risco. ${ }^{62}$ Nesse estudo, Canguilhem não é chamado tão ativamente quanto no anterior a ajudar na construção do quadro teórico-metodológico, mas o fato de que contribuições suas sobre as ciências da vida e da saúde são evocadas ao longo de todo o trabalho afasta a hipótese de que isto se deva a algum tipo de esquecimento ou abandono.

${ }^{57}$ T. Kuhn, A estrutura das revoluçoes científicas (São Paulo: Perspectiva, 1989).

${ }^{58}$ M. T. A. D Coelho e F. N. Almeida, "Conceitos de saúde em discursos contemporâneos de referência científica".

${ }^{59}$ J. R. C. M. Ayres, Epidemiologia e emancipação.

${ }^{60}$ R. B. Mendes-Gonçalves, Prefácio em J. R. C. M. Ayres, Epidemiologia e emancipação.

${ }^{61}$ M. Foucault, A arqueologia do saber (Rio de Janeiro: Forense-Universitária, 1987).

${ }^{62}$ J. R. C. M. Ayres, Sobre o risco: para compreender a epidemiologia, (São Paulo: Hucitec, 1997). 
Como é provável que esteja acontecendo em outras produções no campo da Saúde Coletiva, a contribuição fundamental de sua epistemologia histórica resulta quase como um pressuposto, um ponto de partida tácito - o que, apesar de parecer uma boa explicação, não pode servir de justificativa para a negligência com a retomada crítica de um quadro tão rico e relevante para a Saúde Coletiva.

Penso que, em grande medida, foi esse o caso em "Sobre o risco". Aqui Canguilhem não faz parte centralmente da exposição da arquitetônica metodológica do estudo, ainda que seja chamado a sustentar alguns de seus traços fundamentais, em particular o sentido recorrente da investigação a partir do conceito desde sua forma mais acabada (para apreenderlhe a racionalidade, não a imanência lógica), e os conceitos, de extração bachelardiana, de obstáculo e ruptura epistemológica. O recurso mais relevante ao longo do texto refere-se a algumas de suas agudas discussões sobre as diferenças e vizinhanças entre uma ideologia científica e uma ciência plenamente estabelecida ${ }^{63}$, o conceito de meio e sua importância para as ciências da saúde, ${ }^{64}$ a questão da leitura fisiológica da patologia e seu dogma da continuidade qualitativa entre saúde e doença ${ }^{65}$ e a questão mais contemporânea do organismo como sistema de informação. ${ }^{66}$

Este estudo faz, contudo, um trânsito teórico-metodológico que aponta para outra área de desafios à atualização crítica do quadro canguilhemiano. Trata-se, da mesma forma que se buscou em "Epidemiologia e emancipação" o sentido da ação política por trás das estruturas normativo-paradigmáticas, ir também atrás das interações que conformam as perspectivas subjetivas identificadas nessa ação política. Em outras palavras, buscou-se elucidar nas proposições que validaram os discursos epidemiológicos as pretensões, condições e exigências de validez que construíram sua efetividade comunicacional e legitimação dos sujeitos e instituições que a sustentavam. Com base na hermenêutica de Gadamer ${ }^{67}$ e Ricoeur, ${ }^{68}$ mas especialmente na Teoria da Ação Comunicativa de Habermas, ${ }^{69}$ foi possível superar o que talvez seja também um aspecto do quadro da epistemologia histórica a ser criticamente reconstruído. Se é verdade que Canguilhem considera as interações sociais como determinantes sobre o que faz um cientista em "seu laboratório", é ainda esse indivíduo cientista, portador de uma razão que busca respostas para os problemas colocados por sua ciência, que produzirá os conceitos. Não será esse um traço solipsista que permanece como um obstáculo às respostas que os novos tempos da Saúde Coletiva precisam obter da epistemologia histórica? Não será preciso descobrir de quais diálogos participamos enquanto estamos fazendo uma ciência para poder de fato apreender as pretensões/condições/exigências normativas que nos orientam como seus sujeitos?

Por fim, na segunda vertente desdobrada da TPTS vemos surgir a necessidade de um outro Canguilhem, não tanto o historiador das ciências, mas o filósofo da medicina. A crítica aqui realizada ao paroxismo tecnicista das práticas de atenção à saúde foi dirigido por diversas e inter-relacionadas motivações reconstrutivas - necessidade de uma atenção integral à saúde, humanização das práticas, respeito aos sujeitos em sua diversidade e seus direitos - sintetizadas no conceito de Cuidado. ${ }^{70} \mathrm{O}$ diálogo restringiu-se, assim, praticamente ao Canguilhem de "O normal e o patológico", que, atualizando a máxima de Leriche "A saúde é a vida no silêncio dos órgãos”, nos ensina que a experiência do adoecimento é sempre percebida como obstáculo

${ }^{63} \mathrm{G}$. Canguilhem. Ideologia e racionalidade nas ciências da vida.

${ }^{64}$ G. Canguilhem, O conhecimento da vida (Rio de Janeiro: Forense Universitária, 2012)

${ }^{65} \mathrm{G}$. Canguilhem, O normal e o patológico.

${ }^{66}$ G. Canguilhem, "Epistemology of biology", em F. Delaporte (ed.), A vital rationalist - selected writings from Georges Canguilhem (New York: Zone books, 1994), 67-90.

${ }^{67}$ H. G. Gadamer, Verdade e método: traços fundamentais de uma bermenêutica filosófica.

${ }^{68}$ P. Ricoeur, Del texto a la acción: ensayos de bermenêutica II (Buenos Aires: Fondo de Cultura Económica, 2010).

${ }^{69} \mathrm{~J}$. Habermas, Teoria do agir comunicativo (São Paulo: Martins Fontes, 2012).

${ }_{70}$ J. R. C. M. Ayres, Cuidado: trabalho e interação nas práticas de saúde (Rio de Janeiro: CEPESC; IMS/UERJ; Abrasco, 2011) 
a um padrão normativo anterior e que antecede ontologicamente sua tradução na morfofisiologia. Aquele que nos mostra também que doença não é excesso ou falta de algo que temos na "normalidade", mas diferença e novas possibilidades.

Na maior parte dos meus trabalhos relacionados ao Cuidado, porém, a preocupação maior se deu com as características das interações entre profissionais de saúde e usuários de serviços e, nesse sentido, a concepção de doença (e de saúde), altamente tributária de Canguilhem, como indicado acima, ficou por ser melhor explorada. Houve apenas um trabalho em que avancei um pouco mais nesse sentido: "Uma concepção hermenêutica de saúde". ${ }^{71}$ Aqui está mais explícita a referência a Canguilhem ${ }^{72} \mathrm{e}$, inspirado também pelas reflexões de Gadamer, ${ }^{73}$ semelhantes em muitos sentidos, isto foi o mais longe que logrei caminhar para responder ao inadiável desafio de repensar nossas concepções de saúde e doença. Ali defendo a diferença não apenas de grau ou de qualidade ente elas, senão a diversidade de significado prático mesmo das experiências a que remetem como construções discursivas. Mas ao mesmo tempo em que sustento ser importante levar a sério essa diferença, postulo também a inseparabilidade dessas experiências e suas respectivas expressões discursivas, posto que os adoecimentos e as leituras técnico-científicas que deles fazemos são poderosos intérpretes da compreensão de saúde na qual habitamos e que, como diria Leriche, flui "no silêncio dos órgãos" (e dos preventivistas, eu acresentaria).

Uma decorrência dessa concepção de saúde é que a medicina, a Saúde Coletiva, as práticas de saúde de modo geral, devem realizar, para além e junto de toda construção objetivante do adoecimento, uma verdadeira hermenêutica da saúde, e nós, estudiosos e profissionais de saúde, devemos ser seus cuidadosos intérpretes. Para minha satisfação encontrei uma proposição bastante semelhante de Canguilhem, a que apenas recentemente tive acesso. Deixo, então, a Canguilhem as últimas palavras deste artigo que, afinal, é apenas parte de um grande diálogo que desejamos que prossiga:

A verdade de meu corpo, sua própria constituição ou sua autenticidade de existência, não é uma ideia suscetível de representação. (...) Essa saúde sem ideia, ao mesmo tempo presente e opaca é, no entanto, o que suporta e valida, de fato e em última instância, para mim mesmo e também para o médico enquanto meu médico, o que a ideia do corpo, isto é, o saber médico, pode sugerir como artifício para sustentá-la. Meu médico é aquele que aceita, de um modo geral, que eu o instrua sobre aquilo que só eu estou fundamentado para lhe dizer. (...) Meu médico é aquele que aceita que eu veja nele um exegeta, antes de vê-lo como reparador. ${ }^{74}$

\section{Agradecimento}

À Profa. Maria Novaes, pela generosa ajuda no acesso a algumas fontes bibliográficas e informações sobre o período de Sérgio Arouca e o grupo da Unicamp na década de 1970.

\footnotetext{
${ }^{71}$ J. R. C. M. Ayres, "Uma concepção hermenêutica de saúde".

72 Georges Canguilhem, O normal e o patológico.

${ }^{73}$ H. G. Gadamer, The enigma of health: the art of healing in a scientific age (Stanford: Stanford University Press, 1996).

${ }^{74} \mathrm{G}$. Canguilhem. Escritos sobre a medicina, 45.
} 